\title{
Locating a public good on a sphere
}

Citation for published version (APA):

Chatterjee, S., Peters, H., \& Storcken, T. (2016). Locating a public good on a sphere. Economics Letters, 139, 46-48. https://doi.org/10.1016/j.econlet.2015.12.015

Document status and date:

Published: 01/02/2016

DOI:

10.1016/j.econlet.2015.12.015

Document Version:

Accepted author manuscript (Peer reviewed / editorial board version)

Document license:

CC BY-NC-ND

\section{Please check the document version of this publication:}

- A submitted manuscript is the version of the article upon submission and before peer-review. There can be important differences between the submitted version and the official published version of record.

People interested in the research are advised to contact the author for the final version of the publication, or visit the DOI to the publisher's website.

- The final author version and the galley proof are versions of the publication after peer review.

- The final published version features the final layout of the paper including the volume, issue and page numbers.

Link to publication

\footnotetext{
General rights rights.

- You may freely distribute the URL identifying the publication in the public portal. please follow below link for the End User Agreement:

www.umlib.nl/taverne-license

Take down policy

If you believe that this document breaches copyright please contact us at:

repository@maastrichtuniversity.nl

providing details and we will investigate your claim.
}

Copyright and moral rights for the publications made accessible in the public portal are retained by the authors and/or other copyright owners and it is a condition of accessing publications that users recognise and abide by the legal requirements associated with these

- Users may download and print one copy of any publication from the public portal for the purpose of private study or research.

- You may not further distribute the material or use it for any profit-making activity or commercial gain

If the publication is distributed under the terms of Article $25 \mathrm{fa}$ of the Dutch Copyright Act, indicated by the "Taverne" license above, 
This work is licensed under the Creative Commons Attribution-NonCommercial-NoDerivatives 4.0 International License. To view a copy of this license, visit http://creativecommons.org/licenses/by-nc$\mathrm{nd} / 4.0 /$

\title{
Locating a Public Good on a Sphere
}

\author{
Swarnendu Chatterjee * Hans Peters ${ }^{\dagger} \quad$ Ton Storcken ${ }^{\ddagger}$
}

September 18, 2015

\begin{abstract}
There have been many studies on the location of public goods where the agents are equipped with single-peaked preferences. Generally speaking, single-peakedness of preferences seems to allow for more possibilities and to lead less frequently to dictatorship (Black (1948), Moulin (1980), Kim and Roush (1981), Border and Jordan (1983), Peters et al. (1992)), This paper deals with the problem of finding a location for a public facility on a sphere. We assume that a finite number of agents equipped with single peaked preferences, reaches a decision by voting. We show that the coordinate-wise median rule is not strategy-proof in this domain, which is in contrast with many findings in the literature. Then we prove that any strict strategy-proof and Pareto optimal rule is dictatorial. We also prove that any coalitional strategy-proof and Pareto optimal rule is dictatorial. To prove the dictatorship results we use the ultrafilter technique. Hence we show that the set of decisive coalitions is intersection closed. The problem with only strategy-proofness and Pareto optimality is still open.
\end{abstract}

We start with describing the model together with necessary notes on spherical geometry. In the next section we present implications of strategy-proofness and Pareto optimality in our model. In the following section we prove our main results one assuming coalitional strategy-proof and another assuming strict strategy-proof.

\section{$1 \quad$ Introduction and model}

In our collective decision problem, the set of alternatives is the unit sphere $A=\left\{x \in \mathbb{R}^{3}:|x|=1\right\}$, where $|$.$| denotes Euclidean distance. We first collect$ some useful facts about spherical geometry.

\subsection{Some facts about spherical geometry}

- The distance between two points $x$ and $y$ on the sphere is measured along a great circle, i.e. a circle with radius 1 and as center the origin. A greatcircles is the intersection of a plane through the origin and $A$. Since this distance is a monotonic transformation of Euclidean distance, we simply denote it as $|x-y|$.

*S.chatterjee@maastrichtuniversity.nl

H.Peters@maastrichtuniversity.n!

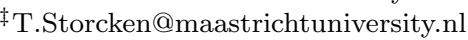


- Observe that for every $x \in A$ there is a unique point in $A$ that has maximal distance to $x$ (diametrically opposite); we denote this point by $\hat{x}$, called the antipodal point of the point $x$.

- We denote the great circle through any two points $x \in A$ and $y \in A$ by $G_{x y}$. If $x$ and $y$ are antipodal, then $G_{x y}=A$.

- For $a, b \in A(a \neq \hat{b})$ we denote the closed (shortest) arc by $[a \frown b]$, clearly $[a \frown b] \subseteq G_{a b}$. Also, $\left.[a \frown b[=[a \frown b] \backslash\{b\}], a \frown b]=[a \frown b] \backslash\{a\},\right] a \frown$ $b[=[a \frown b] \backslash\{a, b\}$. For $a=\hat{b} \in A$, there are infinitely many great-circles through them. Therefore, for $a=\hat{b} \in A$, we define $[a \frown b]=A$. In this case, $[a \frown b[=A \backslash\{b\}], a \frown b]=A \backslash\{a\}], a \frown b[=A \backslash\{a, b\}$.

- For a great-circle $G$ and a point $t \in A \backslash G,(G, t)$ denotes the (open) hemisphere of all points of $A$ on the same side of $G$ as $t$, excluding $G$. The closed hemisphere is denoted by $\overline{(G, t)}$, hence $\overline{(G, t)}=(G, t) \cup G$.

- The perpendicular bisector of a closed arc $[a \frown b]$ is the great-circle that passes through the midpoint of $[a \frown b]$ and is perpendicular to $[a \frown b]$ ( or $G_{a b}$ ).

- A set $C \subseteq A$ is convex if it contains all the arcs $[x \frown y]$ joining any two points $x, y \in C$.

- The convex hull of a set $X$ is the set $C o(X)=\cap\{C: X \subseteq C, C$ convex $\}$.

\subsection{The social choice model}

Now we formulate our social choice model. The set of agents is $N=\{1, \ldots, n\}$ with $n \geq 2$. Each agent $i \in N$ has a single-peaked preference on $A$, characterized by a peak $p(i)$. So, for agent $i$, a point $x \in A$ is weakly preferred to another point $y \in A$ if and only if $|x-p(i)| \leq|y-p(i)|$.

A profile is a vector $p \in A^{N}$, where $p=(p(1), p(2), \ldots, p(n))$. A social choice rule or rule $\phi$ assigns to each $p \in A^{N}$ a collective decision $\phi(p) \in A$. Let $S \subseteq N$. Profiles $p$ and $q$ are $S$-deviations if $p(i)=q(i)$ for all $i \in N \backslash S$. A point $t \in A$ is Pareto optimal for a profile $p \in A^{N}$, there does not exist a point $t^{\prime} \in A \backslash\{t\}$ such that $\left|t^{\prime}-p(i)\right| \leq|t-p(i)|$ for all $i \in N$, with at least one strict inequality. Next we define some desirable properties of $\phi$.

- $\phi$ is manipulable by $S$ if there are $S$-deviations $p, q \in A^{N}$, such that $|\phi(p)-p(i)| \geq|\phi(q)-q(i)|$ for all $i \in S$, where at least one of these inequalities is strict.

- $\phi$ is coalitional strategy-proof if it is not manipulable by any $T \subseteq N$.

- $\phi$ is intermediate strategy-proof if it is not manipulable from any $T$-unanimous profile $p$, i.e. $p(i)=p(j)$ for all $i, j \in T$, to $T$-deviation $q$.

- $\phi$ is strategy-proof if it is not manipulable by singleton coalitions $T$.

- $\phi$ is strict strategy-proof if for all $i \in N$ and $\{i\}$-deviations $p$ and $q$, either $\phi(p)=\phi(q)$ or $|\phi(p)-p(i)|<|\phi(q)-p(i)|$. 
- $\phi$ is intermediate strict strategy-proof if for all T and T-deviations $q$ from a $T$-unanimous profile $p$, we have either $\phi(p)=\phi(q)$ or $|\phi(p)-p(i)|<$ $|\phi(q)-p(i)|$ for all $i \in T$.

- $\phi$ is Pareto optimal if for every $p \in A^{N}, \phi(p)$ is a Pareto optimal point for $p$.

Remark 1 Observe that antipodal points of the peaks can be considered as dips, where the $\operatorname{dip} d(i)$ of agent $i \in N$ is such that $x \in A$ is weakly preferred to $y \in A$ if and only if $|x-d(i)| \geq|y-d(i)|$. Thus, single peaked preferences can also be viewed as single-dipped preferences.

A coalition $S \subseteq N$ is decisive if for every $t \in A$ and every profile $p \in A^{N}$ with $p(i)=t$ for all $i \in S$ we have $\phi(p)=t$. If one particular agent $d$ becomes decisive then she is called the dictator. A rule is dictatorial if there is an agent $d$ such that $\phi(p)=p(d)$ for every $p \in A^{N}$.

We begin our study with rules satisfying strategy-proofness and Pareto optimality.

\section{Strategy-proofness and Pareto optimality}

In this section, rule $\phi$ is assumed to be strategy-proof and Pareto optimal.

Remark 2 Let $p(i) \in H$ for all $i \in N$, where $H$ is a hemisphere. A point $t$ is Pareto optimal for $p$ if and only if $t \in C o(P)$, where $P=\{p(1), p(2), \ldots, p(n)\}$.

Lemma 1 Let $S \subset N$. Then $S$ is decisive or $N \backslash S$ is decisive.

Next we provide an example of a coordinatewise median rule which is Pareto optimal but not strategy-proof.

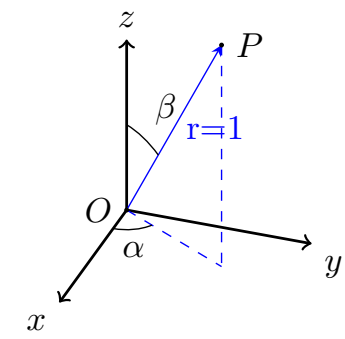

(a) Spherical Coordinate

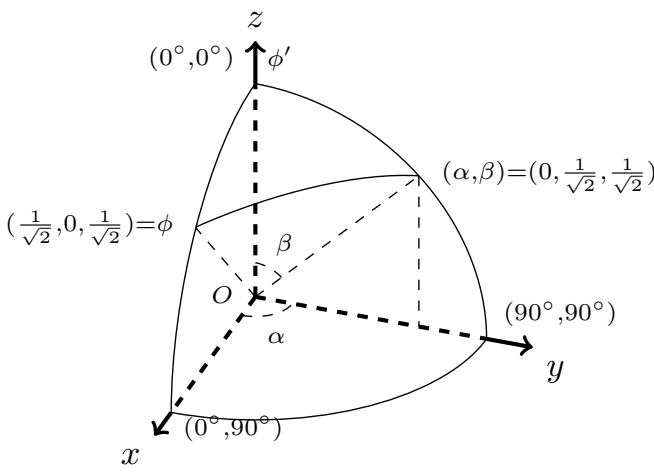

(b) Example

Figure 1

To define a spherical coordinate system, one must choose two orthogonal directions, the polar and the azimuth reference, and an origin point in space. These choices determine a reference plane that contains the origin and is perpendicular to the polar. The spherical coordinates $(\alpha, \beta)$ of a point $P$ (see 
Figure पad) are then defined as follows: Euclidean coordinate of point $P$ is $(\sin \beta \cos \alpha, \sin \beta \sin \alpha, \cos \beta)$. A coordinatewise median rule $F_{\text {coord }}$ takes coordinates of all the peaks $\left(\alpha_{1}, \beta_{1}\right),\left(\alpha_{2}, \beta_{2}\right), \ldots,\left(\alpha_{n}, \beta_{n}\right)$ and then computes medians of both the polar angles median $\left(\beta_{1}, \beta_{2}, \ldots, \beta_{n}\right)=\beta_{\text {med }}$ and azimuth angles $\operatorname{median}\left(\alpha_{1}, \alpha_{2}, \ldots, \alpha_{n}\right)=\alpha_{\text {med }}$. So,

$F_{\text {coord }}(p(1), p(2), \ldots, p(n))=F_{\text {coord }}\left(\left(\alpha_{1}, \beta_{1}\right),\left(\alpha_{2}, \beta_{2}\right), \ldots,\left(\alpha_{n}, \beta_{n}\right)\right)=\left(\alpha_{\text {med }}, \beta_{\text {med }}\right)$.

Example 1 Suppose there are three agents 1,2 , and 3 with peaks at $\left(0^{\circ}, 0^{\circ}\right),\left(0^{\circ}, 90^{\circ}\right)$, $\left(90^{\circ}, 45^{\circ}\right)$ respectively. Corresponding Euclidean coordinates are $(0,0,1),(1,0,0)$, $\left(0, \frac{1}{\sqrt{2}}, \frac{1}{\sqrt{2}}\right)$. Coordinate-wise median rule provides the outcome $\phi=\left(0,45^{\circ}\right)$ (Sphericalcoordinate) or $\phi=\left(\frac{1}{\sqrt{2}}, 0, \frac{1}{\sqrt{2}}\right)$ (Euclidean-coordinate). Now if agent 3 deviates and reports $\left(90^{\circ}, 0^{\circ}\right)$. Then $\phi^{\prime}=\left(0^{\circ}, 0^{\circ}\right)$ (Spherical coordinate) or $\phi^{\prime}=(0,0,1)$. Note that, $\left|\phi-\left(0, \frac{1}{\sqrt{2}}, \frac{1}{\sqrt{2}}\right)\right|^{2}=1$ and $\left|\phi^{\prime}-\left(0, \frac{1}{\sqrt{2}}, \frac{1}{\sqrt{2}}\right)\right|^{2}=2-\sqrt{2}$. So, agent 3 with peak at $\left(90^{\circ}, 45^{\circ}\right)$ can manipulate by reporting $\left(90^{\circ}, 0^{\circ}\right)$. Hence the rule is not strategy-proof.

In what follows, we show that both under strict strategy-proofness and under coalitional strategy-proofness, the set of decisive coalitions is an ultrafilter $\mathcal{D}$ on $N$, i.e.

1. $N \in \mathcal{D}$.

2. for each $S \subseteq N$ either $S \in \mathcal{D}$ or $N \backslash S \in \mathcal{D}$.

3. for all $S, T \in \mathcal{D}$, then $S \cap T \in \mathcal{D}$.

It is well-known and easy to see that an ultrafilter $\mathcal{D}$ contains a unique singleton $\{d\}$, so that $d$ is a dictator.

Remark 3 Suppose $V$ and $W$ are decisive coalitions and $V \cap W$ is not decisive. Then, by Lemma 凹, $N \backslash(V \cap W)$ is decisive. Let $X=V \backslash W, Y=V \cap W$, and $Z=N \backslash V$. So $X \cup Y=V, Y \cup Z=N \backslash(V \backslash W) \supseteq W$ and $X \cup Z=N \backslash(V \cap W)$ are decisive. We use this fact in the following proofs.

\section{Strict strategy-proofness and coalitional strategy- proofness}

Lemma 2 Let $\phi$ be Pareto optimal and strict strategy-proof. If $V$ and $W$ are decisive coalitions, then $V \cap W$ is decisive. 


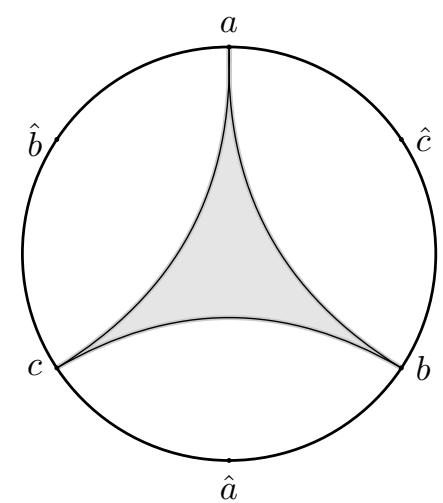

Figure 2: Proof of first half of Lemma 2

Proof. To the contrary assume that $V \cap W$ is not decisive. $X, Y$, and $Z$ are defined as Remark [1. Consider a profile $p$ such that, $p(i)=a$ for all $i \in X$, $p(j)=b$ for all $j \in Y, p(i)=c$ for all $k \in Z$. We denote $p$ as $p=\left(a^{X}, b^{Y}, c^{Z}\right)$. $a, b$ and $c$ are chosen to be equidistant on a great-circle. Next we show that $\phi(p)$ is not on $G_{a b}$

Since $X \cup Y$ is decisive, hence $\phi\left(b^{X \cup Y}, c^{Z}\right)=b$ and $\phi\left(a^{X \cup Y}, c^{Z}\right)=a$, it follows by strict strategy-proofness that

$$
\begin{array}{r}
|a-\phi(p)|<|a-b| \text { or } \phi(p)=b \\
\text { and }|b-\phi(p)|<|b-a| \text { or } \phi(p)=a .
\end{array}
$$

Similarly since $X \cup Z$ is decisive, hence $\phi\left(a^{X \cup Z}, b^{Y}\right)=a$ and $\phi\left(c^{X \cup Z}, b^{Y}\right)=$ $c$, it follows by strict strategy-proofness that

$$
\begin{array}{r}
|c-\phi(p)|<|c-a| \text { or } \phi(p)=a \\
\text { and }|a-\phi(p)|<|a-c| \text { or } \phi(p)=c .
\end{array}
$$

Since $Y \cup Z$ is decisive, hence $\phi\left(a^{X}, b^{Y \cup Z}\right)=b$ and $\phi\left(a^{X}, c^{Y \cup Z}\right)=c$, it follows by strict strategy-proofness that

$$
\begin{array}{r}
|c-\phi(p)|<|c-b| \text { or } \phi(p)=b \\
\text { and }|b-\phi(p)|<|b-c| \text { or } \phi(p)=c .
\end{array}
$$

Suppose $\phi(p)=a$, then equation (B) is not satisfied. Hence $\phi(p) \neq a$, and similarly $\phi(p) \neq b$ and $\phi(p) \neq c$. To satisfy (四)-(B) $\phi(p)$ must belong to the (open) shaded region in Figure $\square$ and the reflection of that region on the other side of the sphere with respect to the great-circle $G_{a b}$. Hence $\phi(p) \notin G_{a b}$.

Let $G_{1}$ and $G_{2}$ be the two hemispheres separated by $G_{a b}$. Assume without loss of generality that $\phi(p) \in G_{1}$. Consider a point $d \in G_{2}$. Let us denote $\left(x^{X}, b^{Y}, c^{Z}\right)$ by $p^{x}$. By Remark $\mathbb{\Omega}, \phi\left(p^{d}\right) \in G_{2}$. Consider a sequence of points $\left\{d_{k}\right\}_{k=1}^{\infty} \in G_{2}$ converging to $a$. As $\overline{G_{2}}$ is compact we may assume that for some subsequence of $\left\{d_{k}\right\}_{k=1}^{\infty}$ the images $f^{k}=\phi\left(p^{d_{k}}\right)$ are converging to a point, say $f^{*}$, in $\overline{G_{2}}$. Without loss of generality we may assume that the original sequence does so. Now, $f^{*} \neq a$, otherwise $\left|f^{k}-a\right|<|\phi(p)-a|$ for large $k$, so $X$ could manipulate by $\left(d_{k}{ }^{X}, b^{Y}, c^{Z}\right)$ at $p$. 


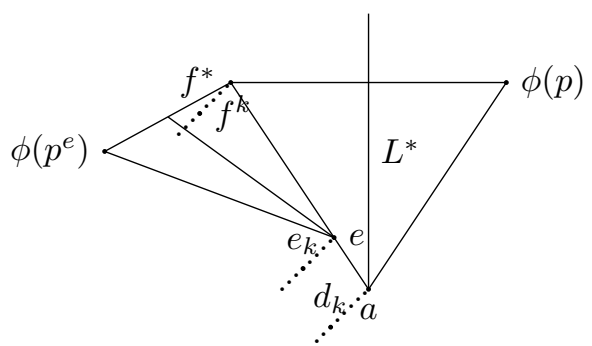

Figure 3: Proof of second half of Lemma 2

Let $L^{*}$ be the perpendicular bisector of $\left[\phi(p) \frown f^{*}\right]$. If $a \in\left(L^{*}, f^{k}\right)$, i.e. if $L^{*}$ separates $a$ and $\phi(p)$, then for large $k$ we have $|a-\phi(p)|>\left|a-f^{k}\right|$ (see Figure [3). So $X$ can manipulate at $p$ to $\left(d_{k}{ }^{X}, b^{Y}, c^{Z}\right)$ which contradicts intermediate strategy-proofness. If $a \in\left(L^{*}, \phi(p)\right)$ (see Figure [i]), then for large $k$ we have some $\epsilon>0$ such that $\left|d_{k}-\phi(p)\right|+\epsilon<\left|d_{k}-f^{*}\right|$ and $\left|f^{k}-f^{*}\right|<\epsilon$. So, $\left|f^{k}-f^{*}\right|+\left|d_{k}-f^{k}\right|>\left|d_{k}-f^{*}\right|$ and therewith $\left|d_{k}-f^{k}\right|+\epsilon>\left|d_{k}-f^{*}\right|$. Hence, $\left|d_{k}-\phi(p)\right|+\epsilon<\left|d_{k}-f^{*}\right|<\left|d_{k}-f^{k}\right|+\epsilon$ and therewith $\left|d_{k}-\phi(p)\right|<$ $\left|d_{k}-f^{k}\right|$. So, $X$ can manipulate at $\left(d_{k}{ }^{X}, b^{Y}, c^{Z}\right)$ to $p$ which also contradicts intermediate strategy-proofness. Hence $a$ must be on the great-circle $L^{*}$.

Consider a point $e$ on $\left[f^{*} \frown a\right]$. Consider $\phi\left(e^{X}, b^{Y}, c^{Z}\right)$. Now $\phi\left(e^{X}, b^{Y}, c^{Z}\right)$ cannot be equal to $f^{*}$ as this would violate intermediate strict strategy-proofness, because $|a-\phi(p)|=\left|a-f^{*}\right|$ where $\phi(p) \neq f^{*}$. Now we can find points $e_{k}$ on $\left[f^{k} \frown d_{k}\right]$ such that $\left\{e_{k}\right\}_{k=1}^{\infty}$ converges to $e$. As, by strategy-proofness, $\phi\left(e_{k}{ }^{X}, b^{Y}, c^{Z}\right)=\phi\left(d_{k}{ }^{X}, b^{Y}, c^{Z}\right)=f^{k}$ it follows like before that $e$ is on the perpendicular bisector of $\left[f^{*} \frown \phi\left(e^{X}, b^{Y}, c^{Z}\right)\right]$. Hence, $\left|e-\phi\left(e^{X}, b^{Y}, c^{Z}\right)\right|=$ $\left|e-f^{*}\right|$. But then $|a-\phi(p)|=\left|a-f^{*}\right|=\left|f^{*}-e\right|+|a-e|=\left|\phi\left(e^{X}, b^{Y}, c^{Z}\right)-e\right|+$ $|a-e|>\left|\phi\left(e^{X}, b^{Y}, c^{Z}\right)-a\right|$ contradicting intermediate strict strategy-proofness. This contradiction ends the proof.

Corollary 1 By Lemmas $\square$ and 回 the collection D of decisive coalitions is an ultrafilter if $\phi$ satisfies strict strategy-proofness and Pareto optimality.

Lemma 3 Let $\phi$ be Pareto optimal and coalitional strategy-proof. If $V$ and $W$ are decisive coalitions, then $V \cap W$ is decisive.

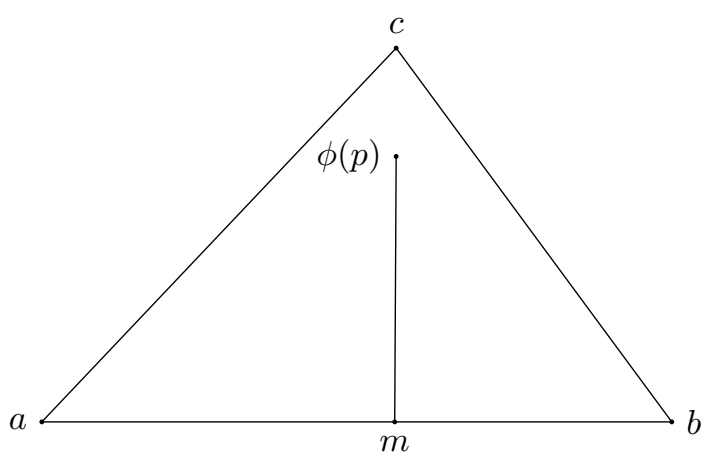

Figure 4: $\operatorname{Co}(\{a, b, c\})$ 
Proof. To the contrary suppose that $V \cap W$ is not decisive. $X, Y$, and $Z$ are defined as Remark 3. Consider a profile $p=\left(a^{X}, b^{Y}, c^{Z}\right)$ with $a, b, c \in A$ (hence agents in $X$ have their peaks at $a$, agents in $Y$ at $b$, and agents in $Z$ at $c)$. Points $a, b$, and $c$ are such that the convex hull $C o(\{a, b, c\})$ formed by them has all the inner angles less than $90^{\circ}$. Since angle between $[a \frown b]$ and $[b \frown c]$ is less than $90^{\circ}$ and also the angle between $[a \frown c]$ and $[b \frown c]$ is less than $90^{\circ}$, the points $a, b, c$ must belong to one hemisphere. So, by Remark $\boldsymbol{\nabla}$, $\phi\left(a^{X}, b^{Y}, c^{Z}\right) \in C o(\{a, b, c\})$.

Suppose the outcome $\phi(p) \notin[a \frown b]$. Then we join $\phi(p)$ with its nearest point $m$ on $[a \frown b]$. Now $|a-m|<|a-\phi(p)|$ and $|b-m|<|b-\phi(p)|$. Hence $X$ and $Y$ can jointly manipulate by deviating to $m$, which is a violation of coalitional strategy-proofness. Thus, $\phi(p) \in[a \frown b]$. Similarly we can show that $\phi(p) \in[c \frown a]$ and $\phi(p) \in[b \frown c]$. But this is not possible. Hence we can conclude that $V \cap W$ must be decisive.

Corollary 2 By Lemmas $\mathbf{\square}$ and 圆 the collection D of decisive coalitions is an ultrafilter if $\phi$ satisfies coalitional strategy-proofness and Pareto optimality.

\section{References}

1. Black, D. (1948): "On the Rationale of Group Decision Making"; The Journal of Political Economy 56, 23 - 34.

2. Black, D. (1958): "The Theory of Committees and Elections"; Cambridge.

3. Border, K. C., and Jordan, J. S. (1983): "Straightforward Elections, Unanimity and Phantom Voters"; The Review of Economic Studies 50, 153 170.

4. Kim KH, Roush FW (1981): "Properties of Consistent Voting Systems"; International Journal of Game Theory, 10, 45 - 52.

5. Moulin H (1980): "On Strategy-Proofness and Single Peakedness"; Public Choice 35: 437- 455 .

6. Öztürk M, Peters H, Storcken T (2013): "Strategy-proof location of a public bad on a disc"; Economics Letters 119: 14 - 16.

7. Öztürk M, Peters H, Storcken T (2014): "On the location of public bads: strategy-proofness under two-dimensional single-dipped preferences"; Economic Theory 56: $83-108$.

8. Öztürk M (2013): "Strategy-proofness and single-dipped preferences"; PhD Thesis, Maastricht University.

9. Peters, H., Stel, H. , and Storcken, T. (1992): "Pareto Optimality, Anonymity, and Strategy-Proofness in Location Problems"; International Journal of Game Theory, 21, 221-235. 